\title{
Review Article \\ Polyphenols in Exercise Performance and Prevention of Exercise-Induced Muscle Damage
}

\author{
Marco Malaguti, Cristina Angeloni, and Silvana Hrelia \\ Department for Life Quality Studies_Alma Mater Studiorum-University of Bologna, Via Irnerio 48, 40126 Bologna, Italy \\ Correspondence should be addressed to Silvana Hrelia; silvana.hrelia@unibo.it
}

Received 27 May 2013; Accepted 2 July 2013

Academic Editor: Tullia Maraldi

Copyright (C) 2013 Marco Malaguti et al. This is an open access article distributed under the Creative Commons Attribution License, which permits unrestricted use, distribution, and reproduction in any medium, provided the original work is properly cited.

\begin{abstract}
Although moderate physical exercise is considered an essential component of a healthy lifestyle that leads the organism to adapt itself to different stresses, exercise, especially when exhaustive, is also known to induce oxidative stress, inflammation, and muscle damage. Many efforts have been carried out to identify dietary strategies or micronutrients able to prevent or at least attenuate the exercise-induced muscle damage and stress. Unfortunately most studies have failed to show protection, and at the present time data supporting the protective effect of micronutrients, as antioxidant vitamins, are weak and trivial. This review focuses on those polyphenols, present in the plant kingdom, that have been recently suggested to exert some positive effects on exercise-induced muscle damage and oxidative stress. In the last decade flavonoids as quercetin, catechins, and other polyphenols as resveratrol have caught the scientists attention. However, at the present time drawing a clear and definitive conclusion seems to be untimely.
\end{abstract}

\section{Introduction}

Physical exercise, as well as nutritional behavior, is now widely considered to be an essential component of a healthy lifestyle. Moreover moderate exercise and an active lifestyle have been demonstrated to be useful in the primary and secondary prevention of cardiovascular diseases [1], type II diabetes [2], metabolic syndrome [3], and neurodegenerative diseases like Alzheimer's disease $[4,5]$. It is now well known that regular and moderate exercise represents a mild source of stress able to induce an adaptive response. More importantly it seems that this adaptive response provides protection against other stressors [6], explaining how the practice of regular and moderate exercise plays a key role in the prevention of chronic and degenerative diseases.

The organism ability to adapt itself to stress is known as hormesis. This term refers to a J-shaped or inverted Ushaped dose-response curve produced by biological systems exposed to a stressor. Radak et al. [7] have firstly extended the hormesis theory to the exercise-induced effects. According to this theory, adaptation occurs only when the stressor dose, exercise bout, is within a specific range and followed by rest period. When the stressor is absent no adaptation can occur. On the other hand when exercise bouts are too heavy or not followed by rest periods (overtraining), pathological conditions as muscle damage, oxidative stress, and inflammation can occur as well. For a comprehensive review on this topic please refer to Radak et al. [8].

After many years of intensive research it is now well documented that exercise induces reactive oxygen species (ROS) production resulting in oxidative stress as clearly demonstrated by the induction of lipid peroxidation [912], superoxide anion generation through xanthine oxidase activation, and the increase in oxidized/reduced glutathione (GSSG/GSH) ratio [13, 14].

Many authors have investigated which metabolic pathways are influenced by exercise and if exercise may induce an adaptive response able to prevent, or at least delay, the onset of degenerative diseases. The potentially harmful condition of imbalance of the redox homeostasis plays a fundamental role in the organism adaptive response to exercise. In 2008, for the first time, Gomez-Cabrera et al. [15] defined moderate exercise as an antioxidant, explaining that the mild burst of ROS, generated by training, acts as a signal responsible for the activation of signaling pathways that lead to the induction of antioxidant enzymes in human tissue. 
Other studies have investigated the pathways involved in this process, and it is now well documented that the major players are nuclear factor $\mathrm{kB}(\mathrm{NF}-\mathrm{kB})$, the phosphoinositide 3-kinase/Akt (PI3 K/Akt), p53, heat shock proteins (HSPs), and mitogen-activated protein kinases (MAPKs) [16-19].

If it is commonly accepted that moderate exercise and training are key components of a healthy lifestyle and help to prevent or delay the onset of pathological conditions, it is now clear that these beneficial effects are lost when the exercise becomes exhaustive, indicating that the exercise intensity and duration are responsible for the beneficial or detrimental effects of physical activity.

A great body of literature has demonstrated that exhaustive exercise causes oxidative stress, inflammatory response, and structural damage to muscle cells, evidenced by an increase in the plasma activity of cytosolic enzymes, namely, lactic dehydrogenase (LDH) and creatine kinase (CK) [11, 20, 21]. So, many studies have investigated the possibility to prevent the exercise-induced oxidative stress and muscle damage through nutritional intervention, mainly using antioxidant vitamins and polyunsaturated fatty acids [22-29].

The effects of both Vitamins $\mathrm{C}$ and $\mathrm{E}$ have been investigated in a wide range of exercise conditions, using a variety of supplementation strategies, timing, and dosage. Even though antioxidant vitamin supplementation seems to be a reasonable strategy to reduce or prevent tissues damage in active muscles, there are only few and weak results able to support this thesis [22].

Thompson et al. [24] demonstrated that an acute supplementation $(1000 \mathrm{mg}$ ) of Vitamin C $2 \mathrm{~h}$ prior to a $90 \mathrm{~min}$ intermittent shuttle running test does not affect the increases in serum CK level. Despite that some authors [23] found an increase in plasma total antioxidant capacity in subjects treated with $1000 \mathrm{mg}$ Vitamin C for 2 weeks prior to $2.5 \mathrm{~h}$ cycling at $60 \% \mathrm{VO}_{2}$ max, others [30] found a reduction in IL-6 and malondialdehyde (MDA) plasma levels in subjects treated with $400 \mathrm{mg}$ Vitamin $\mathrm{C}$ for 2 weeks prior to a $90 \mathrm{~min}$ intermittent shuttle running test. Similarly to Vitamin C, the effects of Vitamin $\mathrm{E}$ on exercise-induced muscles damage are still under debate, and the results of different studies are not in agreement. Cannon et al. [26, 31] found that the supplementation of $800 \mathrm{IU}$ of $\alpha$-tocopherol for 48 days does not prevent plasma CK release due to $45 \mathrm{~min}$ downhill running in young men, even though it reduces the secretion of IL- $1 \beta$ and IL- 6 . Two studies reported a positive effect of Vitamin E on exercise-induced muscles damage; Beaton et al. [25] and McBride et al. [32] found, respectively, that 30 days and 14 days supplementation of 1200 IU $\alpha$-tocopherol reduces CK level in serum and plasma after different exercises. These results disagree with those published by Avery et al. [33] which found that 1200 IU $\alpha$-tocopherol, 21 days before and 10 days after exercise, increases CK serum level when subjects undergo exercise bouts.

When Vitamins $\mathrm{C}$ and $\mathrm{E}$ are supplemented in combination some positive effect can be obtained, but, as recently reviewed [22], for each study providing positive effects [34] there are other studies that provide no effect $[35,36]$.

Only recently the attention has been shifted to the effects of nutraceutical bioactive compounds as polyphenols.
Polyphenols are a class of organic chemical compounds, mainly found in plants, characterized by the presence of multiples of phenol structural units. Recently a great body of literature has underlined a potential relationship between bioactive compounds from plant foods and the prevention of cardiovascular and neurodegenerative diseases and other pathological conditions [37-41].

This review will summarize some of the actual knowledge on polyphenolic compounds that have been demonstrated both to exert a significant effect in exercise-induced muscle damage and to play a biological/physiological role in improving physical performance.

\section{Flavonoids}

Among nutraceutical compounds, flavonoids are the mainly studied ones for their positive effects on human health. Some of them have been proposed to be beneficial in exercise and exercise performance. Flavonoids are a family of plant bioactive compounds that share a common backbone. The flavonoid family includes many different subclasses: flavones, flavonols, flavanones, flavanones, isoflavones, and anthocyanidins; in Table 1 some examples are reported for each subclass.

On the left column flavonoid subclasses are reported; on the right some examples for each subclass are listed.

2.1. Flavonols. Flavonols are present in human nutrition as both glycosides and aglycone forms, and it has been estimated that the daily intake is within the range of $20-50 \mathrm{mg} / \mathrm{die}$ in Western population. Of these flavonols quercetin (Figure 1) accounts for about $13.82 \mathrm{mg} /$ die [42], resulting in being one of the most abundant flavonols in Western diet.

Quercetin, mainly present as quercetin glycosides (rutin, spiraeoside, troxerutin quercitrin, isoquercitin, and hyperoside), is widely distributed in plant food; it is found in apples, berries, onions, grapes, tea, and tomatoes as well as in some medicinal plants as Hypericum perforatum and Gingko biloba [43-46].

Recent studies suggest that quercetin bioavailability is much higher than that originally thought [47]. Quercetin, assumed both as purified dietary supplement or as natural food source, has been clearly demonstrated to increase its plasma levels in humans, even though a high interindividual variability in plasma quercetin response has been reported [48-52]. Quercetin aglycone is a lipophilic molecule able to diffuse through the enterocyte membranes. Quercetin glucosides are easily hydrolyzed both in the mouth, during chewing, and in the gut, thanks to beta-glucosidase enzymes [53]. The overall result is that quercetin absorbed as aglycone is much higher than that expected from its food content [47].

Quercetin and other flavonoids have been reported to exert a variety of biological activities often related to their antioxidant nature. McAnulty et al. [54] have investigated the effects of quercetin supplementation in cycling athletes. Subjects were supplemented with $1000 \mathrm{mg} /$ die quercetin or placebo for 6 weeks before and during 3 days in which they cycle for $3 \mathrm{~h} /$ die. In blood and plasma, F2-isoprostanes, 
TABLE 1: Flavonoid classification.

\begin{tabular}{lc}
\hline Flavonoid subclasses & Representative compounds \\
\hline Flavonols & Quercetin, Kaempferol \\
Flavones & Apigenin, Luteolin \\
Flavanols & Epicatechin, Gallocatechin \\
Flavanones & Naringenin, Hesperidin \\
Isoflavones & Daidzein, Genistein \\
Anthocyanidins & Cyanidin \\
\hline
\end{tabular}<smiles>O=c1c(O)c(-c2ccc(O)c(O)c2)oc2cc(O)cc(O)c12</smiles>

Figure 1: Quercetin structure. Quercetin $\left(3,5,7,3^{\prime}, 4^{\prime}\right.$-pentahydroxyflavone) is a typical flavonol-type flavonoid and forms the backbone for many other flavonoids. Flavonoids are characterized by 2 benzene rings connected by an oxygen-containing pyrene ring.

nitrite, ferric-reducing ability, trolox equivalent antioxidant capacity, and C-reactive protein were analyzed before and after exercise. The authors concluded that cycling induces a strong increase in blood biomarkers of oxidative stress and inflammation, but, despite previous data demonstrating potent antioxidant actions of quercetin in in vitro and animal models [55-59], long-term quercetin supplementation was not able to exert any preventive effect on exercise-induced oxidative stress and inflammation biomarkers.

Similar conclusions have been reached when the effects of quercetin in association with catechin, isoquercetin, and PUFA were evaluated in an acute crossover study involving 20 endurance athletes supplemented with an oral dose providing $1000 \mathrm{mg}$ quercetin [60]. Athletes were supplemented $15 \mathrm{~min}$ prior to a 2-hour run. Authors analyzed before, immediately after, and one hour after exercise plasma quercetin level, Creactive protein, IL- 6 , and other cytokines and inflammatory biomarkers, confirming a good quercetin bioavailability but supporting that it does not prevent postexercise inflammation.

In another study [61] the effects of quercetin on inflammation and exercise-induced muscle damage in 39 trained cyclists were evaluated. In this study quercetin was provided in association with Vitamin C, niacinamide, and folic acid (Q) or in association with Vitamin C, niacinamide, folic acid, catechin, isoquercetin, and PUFA (Q-EGCG) for 2 weeks before, during, and 1 week after a 3 days period in which the subject cycled for $3 \mathrm{~h} /$ die. Q-EGCG association was specifically designed to improve quercetin bioavailability and extend its bioactive effects. Results confirm those previously published [54], showing that a long-term quercetin (Q) supplementation is not able to modulate serum C-reactive protein level and plasma IL-6 concentration and prevent
CK relies. The Q-EGCG association decreased almost all biomarkers but not CK levels.

Recently Askari et al. [62] published a double-blind clinical trial on 60 male students with an athletic history of at least 3 years. They found that $500 \mathrm{mg}$ quercetin plus $250 \mathrm{mg}$ Vitamin C daily treatment lasting for 8 weeks was able to improve some markers such as lean body mass, basal metabolic rate, and total energy expenditure. In a previous study the same authors showed that quercetin plus Vitamin $\mathrm{C}$ treatment reduced CK plasma levels after treadmill exercise [63].

Beside the possibility to partially prevent exerciseinduced muscle damage and inflammation, in the last decade a considerable effort has been performed to analyze the possibility that quercetin supplementation could improve aerobic exercise performance in human.

The rationale behind this hypothesis is given by the knowledge that some polyphenols as catechins, resveratrol, quercetin, and curcumin have been shown to activate sirtuins (SIRT1). SIRT1 activation modulates a variety of biological and physiological processes including skeletal muscle function and mitochondria biogenesis $[64,65]$.

Early human and animal studies reported a correlation between quercetin supplementation, endurance capacity, and mitochondrial biogenesis improvement. Davis et al. [66] published promising results showing that 7 days quercetin treatment (12.5 or $25 \mathrm{mg} / \mathrm{kg}$ b.w.) increases the expression of genes associated with mitochondrial biogenesis (PGC-1a and SIRT1), mitochondrial DNA content, and cytochromeC concentration, both at muscle and brain levels in mice. Beside these biological data, quercetin-treated mice showed a significantly higher time to fatigue, in a treadmill running test, than their placebo-treated counterparts. A more recent study has evaluated quercetin ability to increase endurance capacity and $\mathrm{VO}_{2}$ max in a cross-over protocol on healthy but untrained volunteers [67]. Data indicate that a 7 days $1000 \mathrm{mg} /$ die quercetin supplementation is responsible for an improvement (13.2\%) in time to fatigue, during a cycling test, and for a $3.9 \%$ increase in $\mathrm{VO}_{2}$ max. Authors hypothesized a quercetin-induced increase in mitochondrial biogenesis that would lead to an increase in endurance capacity through a shift toward fat oxidation during exercise, but they did not investigate any mitochondrial biogenesis biomarkers.

Other studies have analyzed the effect of quercetin on exercise performance, some reporting positive effects [68, 69], while others do not [70-73], but to our knowledge an increase in mitochondrial biogenesis has not been reported in human even though Neiman et al. [68] have shown a modest and insignificant increase in relative mitochondrial DNA copy number following quercetin supplementation.

In a recent meta-analysis Kressler et al. [74] have demonstrated that quercetin can improve endurance capacity in humans, but they concluded that the benefit magnitude is only trivial to small. Because the "mitochondrial biogenesis" theory that could explain the quercetin-induced endurance capacity has not been demonstrated, some other mechanisms have been suggested. According to its ability to bind and act as antagonist at adenosine receptor level, quercetin may improve exercise performance in a caffeine-like manner 
<smiles>Oc1cc(O)c2c(c1)OC(c1ccc(O)c(O)c1)C(O)C2</smiles><smiles>O=C(O[C@H]1Cc2c(O)cc(O)cc2O[C@@H]1c1cc(O)c(O)c(O)c1)c1cc(O)c(O)c(O)c1</smiles>

(-)-gallocatechin gallate<smiles>O=C(O[C@H]1Cc2c(O)cc(O)cc2O[C@@H]1c1cc(O)c(O)c(O)c1)c1cc(O)c(O)c(O)c1</smiles>

(-)-epigallocatechin gallate (EGCG)<smiles>O=C(O[C@H]1Cc2c(O)cc(O)cc2O[C@@H]1c1ccc(O)c(O)c1)c1cc(O)c(O)c(O)c1</smiles>

(-)-epicatechin gallate

Figure 2: Chemical structure of the main catechins. Catechins are characterized by two benzene rings and a dihydropyran heterocycle with a hydroxyl group in position 3. Thanks to the presence of this hydroxyl group catechins are also called flavan-3-ol. Catechin gallates are gallic acid esters of the catechins as epigallocatechin gallate and gallocatechin gallate, which are typically found in tea.

$[75,76]$. However, up to now, this hypothesis has still to be demonstrated, and the only study that has compared caffeine versus quercetin for their ability to improve exercise performance in the heat has failed to find any significant result [77].

2.2. Catechins. Although quercetin is the most studied flavonoid in relation to exercise, other molecules are under investigation for their ability to prevent exercise-induced muscle damage and to affect physical performance. Among them catechins have shown to exert some effects at least in animal models.

As all other flavonoids, catechins represent a family of plant secondary metabolites and belong to the flavanols subclass. Catechins (Figure 2) are easily found in edible foods and plants such as green tea and cacao. Catechin family consists mainly of epigallocatechin gallate (EGCG), gallocatechin gallate, and epicatechin gallate and have been demonstrated to be bioavailable and to possess various biological properties such as cardioprotective $[78,79]$, antiatherogenic [80], and anticarcinogenic effects $[81,82]$.

Some evidence on catechins ability to modulate exerciseinduced muscle damage is rising. Haramizu et al. [83] have recently shown that 8 weeks catechins treatment is able to attenuate loss of muscle force, exercise-induced muscle damage, and oxidative stress biomarkers (CK, LDH, MDA) and to significantly sustain GSH/GSSG ratio after downhill running exercise in senescence-accelerated mice.

Catechins ability to modulate the exercise performance, both in animals and humans, has also been investigated. Murase et al. [84] have shown that green tea extract improves, in a dose-dependent manner, the time to exhaustion in BALB/c mice undergoing a swimming test after 7 weeks treatment. They have also demonstrated, through indirect calorimetry and biochemical analysis, that green tea extract induces a more efficient use of lipids as suggested by the increase in oxygen consumption, $\beta$-oxidation activity in muscle, and fat oxidation, suggesting that the green tea extract-induced lipid oxidation and mobilization are responsible for the increase in endurance capacity. These findings have been deepened, and recently it has been observed that EGCG treatment increases the expression of genes involved in mitochondrial fat oxidation at muscle level in high-fat fed mice [85]. Although most studies on green tea have been performed in animals, a considerable amount of data are now available in humans. Dulloo et al. [86] showed that a green tea extract rich in catechins and caffeine increases the daily energy expenditure in humans. More recently, an acute dose of green tea extract has been evaluated on healthy untrained men in a 30 min cycling test at $60 \% \mathrm{VO}_{2} \max$ [87]. Results demonstrated that green tea extract improves fat oxidation and insulin sensitivity during moderate exercise. 
Other recent findings report that short-term EGCG supplementation increases $\mathrm{VO}_{2} \max$ in adult humans [88], while Dean et al. [89] concluded that 6 days EGCG treatment does not significantly affect fat oxidation during a $60 \mathrm{~min}$ cycling exercise at $60 \% \mathrm{VO}_{2}$ max in moderately well-trained men. In a randomized, double-blind crossover study, 10 endurance-trained subjects exercised for 2 hours at $50 \%$ of their maximal power output before and after 3 weeks of green tea extract supplementation [90]. The treatment did not influence fat and energy metabolism biomarkers (oxygen uptake, respiratory exchange ratio, and energy expenditure), cytokines and inflammatory parameters (IL-6, C-reactive protein), and oxidative stress biomarkers (thiobarbituric acid-reactive substances, oxidized LDL). However,plasma CK level was significantly reduced. Recently Jowko at al. [91] published data obtained treating a group of 16 soccer players with a single dose of $640 \mathrm{mg}$ green tea catechins. Athletes involved in the study performed a muscle-endurance test consisting in 3 bouts to exhaustion of bench press and back squat. Prior to and after exercise test plasma levels of thiobarbituric acid-reacting substances, uric acid, total catechins, total antioxidant status, and CK activity were analyzed.

None of the analyzed biomarkers was affected by the ingestion of green tea catechins, suggesting that the $640 \mathrm{mg}$ dose was too low to attenuate exercise-induced oxidative stress and muscle damage. Green tea catechins-treated players were able to perform a higher number of lift repetitions during the test.

Taken together, data from available studies seem to suggest that catechins can improve physical performance particularly in term of endurance capacity and $\mathrm{VO}_{2}$ max in untrained subjects, but the same results cannot be reached in physically active people and well-trained athletes.

\section{Other Polyphenols}

Resveratrol is a well-known bioactive compound able to induce a wide variety of biological responses. It has shown beneficial effects against most degenerative and cardiovascular diseases from atherosclerosis, hypertension, ischemia/reperfusion, heart failure, diabetes, obesity, aging and neurodegenerative diseases $[40,92]$. Resveratrol, 3,5, $4^{\prime}$ trihydroxystilbene (Figure 3), is a natural phenol present in grape skin and seeds and in grape-derived products like red wine.

Only few studies have investigated resveratrol ability to modulate exercise performance and some evidence suggests that it could play a role improving endurance capacity. It has been demonstrated that after 12 weeks treatment resveratrol prevents the decline in running time to exhaustion, in oxygen consumption, and in lipid oxidation in a senescence-accelerated mice model (SAMP1). Data shown in this study demonstrate that the resveratrol induction of mitochondrial biogenesis (suggested by the mRNA levels of genes involved in mitochondrial biogenesis and energy metabolism, namely, peroxisome proliferator-activated receptor coactivator-1, cytochrome-C,

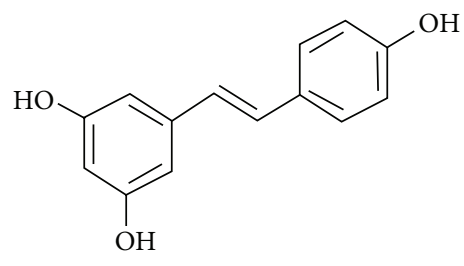

FIGURE 3: Resveratrol structure. Resveratrol (3,5,4'-trihydroxystilbene) belongs to the stilbene group. It exists both as cis- and transisomers.

and medium-chain acyl-CoA dehydrogenase) is responsible for the prevention of ageing-related performance impairment [93]. Accordingly, Dal-Ros et al. [94] have recently demonstrated that chronic red wine polyphenols intake prevents aging-induced performance decline in rats.

Recently some authors have focused their interest on the effect of caffeic acid, especially in its phenethyl ester form (CAPE) (Figure 4). Shen et al. [95] demonstrated that $10 \mathrm{mg} / \mathrm{kg}$ b.w. CAPE oral treatment protects rat muscle tissues from exercise-induced damages. In this study the protocol was represented by an intermittent downhill eccentric exercise able to induce both muscle damages and inflammation as demonstrated by the increase in CK serum level, NF-kB activation, iNOS and COX-2 expression, and IL- $\beta$ level. Moreover, an ex vivo study by Chen et al. [96] shows that CAPE exhibits protective effect against hyperthermal stress, known to impair endurance capacity, in isolated peripheral blood mononuclear cells from competitive cyclists. Pretreatment of mononuclear cells with CAPE reduced hyperthermiainduced necrosis, superoxide production, glutathione depletion, and intracellular superoxide anion production in a dosedependent manner.

Beside studies on single polyphenols, some researches have been focused on the effects of polyphenol mixtures obtained from fruits, plants, or algae. Hurst et al. [97] have investigated the effects of a blueberry extract on skeletal muscle cultured cells showing a dose-dependent protective effect on oxidative stress. Furthermore, Nakazato et al. [98] found that rats fed an apple polyphenol-enriched diet for 3 weeks showed a better oxidative stress biomarkers profile (thiobarbituric acid reactive substances and protein carbonyls), a lower force deficit, and earlier recovery after strenuous lengthening muscle contractions with respect to their control counterparts. Promising results have been published by Swamy et al. [99] on the effect of pomegranate peel extract supplementation in rats. In this study rats were supplemented for 28 days with $25 \mathrm{mg} /$ die pomegranate peel extract, rich in polyphenols, and were forced to swim until exhaustion. Interestingly, they recorded a strong increase in time to exhaustion among rats fed pomegranate extract with respect to their control counterparts. Authors also found that pomegranate extract fed rats had a higher glycogen and ATP muscular content with respect to controls, and they hypothesized that pomegranate polyphenols are responsible for a better glucose utilization resulting in a longer swimming time to exhaustion. Moreover they found that $\mathrm{LDH}$ and 
<smiles>O=C(/C=C/c1ccc(O)c(O)c1)OCCc1ccccc1</smiles>

FIgURE 4: Caffeic acid phenethyl ester (CAPE) structure. CAPE is a polyphenolic compound primarily found in propolis.

CPK serum levels were reduced in pomegranate extract fed rats, suggesting a protective role of pomegranate polyphenols against exhaustive exercise-induced muscle damage.

Dark-chocolate polyphenols have been ascribed to be responsible for some positive effects of dark-chocolate consumption during exercise. A study investigated the effects of dark-chocolate ( $80 \mathrm{~g} / \mathrm{die}$ for 2 weeks) consumption on oxidative stress biomarkers after prolonged exhaustive exercise. Plasma F2-isoprostanes were significantly lower both at exhaustion and after 1 hour recovery in dark-chocolatesupplemented subjects with respect to their control counterparts. Moreover dark-chocolate consumption was associated with lower oxidized low-density lipoprotein levels before and after exercise and with an increase in free fatty acids levels during exercise, even though the time to exhaustion was not significantly affected [100]. Similar conclusions were drawn when Davison et al. [101] investigated the acute effects of preexercise dark-chocolate consumption. In this study dark chocolate prevents the exercise-induced increase in plasma F2-isoprostane. These results suggest that dark-chocolate intake reduces exercise-induced oxidative stress biomarkers.

Recently it has been found that Ecklonia cava (a species of brown alga present in the ocean of Japan and Korea) polyphenols acute preexercise supplementation induces a slight but significant increase in time to exhaustion in healthy human subjects [102].

\section{Conclusion}

Overall, the available literature seems to suggest that nutraceutical bioactive compounds as polyphenols, known for their effects on degenerative and chronic diseases, can also provide protection against exercise-induced muscle damage and oxidative stress thanks to their antioxidant and antiinflammatory properties. However the possibility to improve the exercise performances remains unclear. Even though this topic is extremely fascinating and has attracted a great research effort scientific data do not allow to draw a clear conclusion. On one hand, in vitro and in vivo animal studies suggest that polyphenols could really play a role in improving endurance performance; on the other hand, most human trials do not support this hypothesis and have failed to demonstrate that nutraceuticals as quercetin, catechins, or resveratrol can really affect exercise performance and $\mathrm{VO}_{2}$ max. The reason for this discrepancy has still to be fully elucidated; however, some hypotheses are possible. Human studies often differ from each other in the training level of enrolled subjects; some studies have been carried on well-trained athletes while others on healthy but untrained subjects. Among recent studies those involving untrained subjects seem to have obtained better results on improving endurance capacity, although Kressler et al. [74], in their meta-analysis on quercetin, suggest that the variability among studies does not appear to be associated with the initial subject fitness level. Moreover while quercetin and catechins effects have been investigated both in animal and in human studies other polyphenols need to be further studied in human trials to reach a clear and unambiguous conclusion.

\section{Acknowledgments}

The authors wish to thank Dr. Antonello Lorenzini for his precious comments and suggestions and Fondazione del Monte di Bologna e Ravenna (Italy) for grant support.

\section{References}

[1] M. L. Daviglus, D. M. Lloyd-Jones, and A. Pirzada, "Preventing cardiovascular disease in the 21st century: therapeutic and preventive implications of current evidence," American Journal of Cardiovascular Drugs, vol. 6, no. 2, pp. 87-101, 2006.

[2] M. Y. Bertram, S. S. Lim, J. J. Barendregt, and T. Vos, "Assessing the cost-effectiveness of drug and lifestyle intervention following opportunistic screening for pre-diabetes in primary care," Diabetologia, vol. 53, no. 5, pp. 875-881, 2010.

[3] T. Church, "Exercise in obesity, metabolic syndrome, and diabetes," Progress in Cardiovascular Diseases, vol. 53, no. 6, pp. 412-418, 2011.

[4] S. Deweerdt, "Prevention: activity is the best medicine," Nature, vol. 475, no. 7355, pp. S16-S17, 2011.

[5] B. F. Hurley, E. D. Hanson, and A. K. Sheaff, "Strength training as a countermeasure to aging muscle and chronic disease," Sports Medicine, vol. 41, no. 4, pp. 289-306, 2011.

[6] L. L. Ji, M. Gomez-Cabrera, and J. Vina, "Role of free radicals and antioxidant signaling in skeletal muscle health and pathology," Infectious Disorders, vol. 9, no. 4, pp. 428-444, 2009.

[7] Z. Radak, H. Y. Chung, and S. Goto, "Exercise and hormesis: oxidative stress-related adaptation for successful aging," Biogerontology, vol. 6, no. 1, pp. 71-75, 2005.

[8] Z. Radak, H. Y. Chung, E. Koltai, A. W. Taylor, and S. Goto, "Exercise, oxidative stress and hormesis," Ageing Research Reviews, vol. 7, no. 1, pp. 34-42, 2008.

[9] A. Mastaloudis, S. W. Leonard, and M. G. Traber, "Oxidative stress in athletes during extreme endurance exercise," Free Radical Biology and Medicine, vol. 31, no. 7, pp. 911-922, 2001.

[10] A. Steensberg, J. Morrow, A. D. Toft, H. Bruunsgaard, and B. K. Pedersen, "Prolonged exercise, lymphocyte apoptosis and F2isoprostanes," European Journal of Applied Physiology, vol. 87, no. 1 , pp. 38-42, 2002.

[11] M. Malaguti, C. Angeloni, N. Garatachea et al., "Sulforaphane treatment protects skeletal muscle against damage induced by exhaustive exercise in rats," Journal of Applied Physiology, vol. 107, no. 4, pp. 1028-1036, 2009.

[12] J. W. Navalta, B. K. McFarlin, and T. S. Lyons, "Does exercise really induce lymphocyte apoptosis?" Frontiers in Bioscience, vol. 2, pp. 478-488, 2010.

[13] J. Sastre, M. Asensi, E. Gasco et al., "Exhaustive physical exercise causes oxidation of glutathione status in blood: prevention by antioxidant administration," American Journal of Physiology, vol. 263, no. 5, part 2, pp. R992-R995, 1992. 
[14] J. Viña, A. Gimeno, J. Sastre et al., "Mechanism of free radical production in exhaustive exercise in humans and rats; role of xanthine oxidase and protection by allopurinol," IUBMB Life, vol. 49, no. 6, pp. 539-544, 2000.

[15] M. Gomez-Cabrera, E. Domenech, and J. Viña, "Moderate exercise is an antioxidant: upregulation of antioxidant genes by training," Free Radical Biology and Medicine, vol. 44, no. 2, pp. 126-131, 2008.

[16] L. L. Ji, "Modulation of skeletal muscle antioxidant defense by exercise: role of redox signaling," Free Radical Biology and Medicine, vol. 44, no. 2, pp. 142-152, 2008.

[17] J. P. Morton, A. C. Kayani, A. McArdle, and B. Drust, "The exercise-induced stress response of skeletal muscle, with specific emphasis on humans," Sports Medicine, vol. 39, no. 8, pp. 643-662, 2009.

[18] S. Sachdev and K. J. A. Davies, "Production, detection, and adaptive responses to free radicals in exercise," Free Radical Biology and Medicine, vol. 44, no. 2, pp. 215-223, 2008.

[19] M. Gomez-Cabrera, J. Viña, and L. L. Ji, "Interplay of oxidants and antioxidants during exercise: implications for muscle health," Physician and Sportsmedicine, vol. 37, no. 4, pp. 116-123, 2009.

[20] R. B. Armstrong, R. W. Ogilvie, and J. A. Schwane, "Eccentric exercise-induced injury to rat skeletal muscle," Journal of Applied Physiology Respiratory Environmental and Exercise Physiology, vol. 54, no. 1, pp. 80-93, 1983.

[21] L. M. Popovic, N. R. Mitic, I. Radic et al., "The effect of exhaustive exercise on oxidative stress generation and antioxidant defense in guinea pigs," Advances in Clinical and Experimental Medicine, vol. 21, no. 3, pp. 313-320, 2012.

[22] C. McGinley, A. Shafat, and A. E. Donnelly, "Does antioxidant vitamin supplementation protect against muscle damage?" Sports Medicine, vol. 39, no. 12, pp. 1011-1032, 2009.

[23] G. Davison and M. Gleeson, "The effect of 2 weeks vitamin C supplementation on immunoendocrine responses to $2.5 \mathrm{~h}$ cycling exercise in man," European Journal of Applied Physiology, vol. 97, no. 4, pp. 454-461, 2006.

[24] D. Thompson, C. Williams, S. J. McGregor et al., "Prolonged vitamin $\mathrm{C}$ supplementation and recovery from demanding exercise," International Journal of Sport Nutrition, vol. 11, no. 4, pp. 466-481, 2001.

[25] L. J. Beaton, D. A. Allan, M. A. Tarnopolsky, P. M. Tiidus, and S. M. Phillips, "Contraction-induced muscle damage is unaffected by vitamin E supplementation," Medicine and Science in Sports and Exercise, vol. 34, no. 5, pp. 798-805, 2002.

[26] J. G. Cannon, S. N. Meydani, R. A. Fielding et al., "Acute phase response in exercise. II. Associations between vitamin E, cytokines, and muscle proteolysis," American Journal of Physiology, vol. 260, no. 6, pp. R1235-R1240, 1991.

[27] E. Filaire, A. Massart, M. Rouveix, H. Portier, F. Rosado, and D. Durand, "Effects of 6 weeks of n-3 fatty acids and antioxidant mixture on lipid peroxidation at rest and postexercise," European Journal of Applied Physiology, vol. 111, no. 8, pp. 1829-1839, 2011.

[28] M. Malaguti, M. Baldini, C. Angeloni, P. Biagi, and S. Hrelia, "High-protein-PUFA supplementation, red blood cell membranes, and plasma antioxidant activity in volleyball athletes," International Journal of Sport Nutrition and Exercise Metabolism, vol. 18, no. 3, pp. 301-312, 2008.

[29] T. Phillips, A. C. Childs, D. M. Dreon, S. Phinney, and C. Leeuwenburgh, "A dietary supplement attenuates IL-6 and
CRP after eccentric exercise in untrained males," Medicine and Science in Sports and Exercise, vol. 35, no. 12, pp. 2032-2037, 2003.

[30] D. Thompson, C. Williams, M. Kingsley et al., "Muscle soreness and damage parameters after prolonged intermittent shuttlerunning following acute vitamin C supplementation," International Journal of Sports Medicine, vol. 22, no. 1, pp. 68-75, 2001.

[31] J. G. Cannon, S. F. Orencole, R. A. Fielding et al., "Acute phase response in exercise: interaction of age and vitamin $\mathrm{E}$ on neutrophils and muscle enzyme release," American Journal of Physiology, vol. 259, no. 6, part 2, pp. R1214-R1219, 1990.

[32] J. M. McBride, W. J. Kraemer, T. Triplett-McBride, and W. Sebastianelli, "Effect of resistance exercise on free radical production," Medicine and Science in Sports and Exercise, vol. 30, no. 1, pp. 67-72, 1998.

[33] N. G. Avery, J. L. Kaiser, M. J. Sharman et al., "Effects of vitamin $\mathrm{E}$ supplementation on recovery from repeated bouts of resistance exercise," The Journal of Strength \& Conditioning Research, vol. 17, no. 4, pp. 801-809, 2003.

[34] D. M. Bailey and D. Thompson, "Supplemental ascorbate and exercise-induced IL-6 metabolism: focus on Fenton chemistry and redox-regulation of vascular homeostasis (multiple letters)," European Journal of Applied Physiology, vol. 94, no. 4, pp. 487-490, 2005.

[35] C. P. Fischer, N. J. Hiscock, M. Penkowa et al., "Supplementation with vitamins $\mathrm{C}$ and $\mathrm{E}$ inhibits the release of interleukin- 6 from contracting human skeletal muscle," Journal of Physiology, vol. 558, part 2, pp. 633-645, 2004.

[36] C. Yfanti, C. P. Fischer, S. Nielsen et al., "Role of vitamin C and E supplementation on IL-6 in response to training," Journal of Applied Physiology, vol. 112, no. 6, pp. 990-1000, 2012.

[37] C. Angeloni, E. Leoncini, M. Malaguti, S. Angelini, P. Hrelia, and S. Hrelia, "Modulation of phase II enzymes by sulforaphane: implications for its cardioprotective potential," Journal of Agricultural and Food Chemistry, vol. 57, no. 12, pp. 5615-5622, 2009.

[38] G. Davì, F. Santilli, and C. Patrono, "Nutraceuticals in diabetes and metabolic syndrome," Cardiovascular Therapeutics, vol. 28, no. 4, pp. 216-226, 2010.

[39] C. Fimognari, M. Lenzi, and P. Hrelia, "Chemoprevention of cancer by isothiocyanates and anthocyanins: mechanisms of action and structure-activity relationship," Current Medicinal Chemistry, vol. 15, no. 5, pp. 440-447, 2008.

[40] N. A. Kelsey, H. M. Wilkins, and D. A. Linseman, "Nutraceutical antioxidants as novel neuroprotective agents," Molecules, vol. 15, no. 11, pp. 7792-7814, 2010.

[41] K. B. Pandey and S. I. Rizvi, "Plant polyphenols as dietary antioxidants in human health and disease," Oxidative Medicine and Cellular Longevity, vol. 2, no. 5, pp. 270-278, 2009.

[42] J. Cao, Y. Zhang, W. Chen, and X. Zhao, "The relationship between fasting plasma concentrations of selected flavonoids and their ordinary dietary intake," British Journal of Nutrition, vol. 103, no. 2, pp. 249-255, 2010.

[43] USDA, "Database for the Flavonoid Content of Selected Foods," http://www.ars.usda.gov/SP2UserFiles/Place/12354500/Data/ Flav/Flav_R03.pdf .

[44] S. H. Häkkinen, S. O. Kärenlampi, I. M. Heinonen, H. M. Mykkänen, and A. R. Törronen, "Content of the flavonols quercetin, myricetin, and kaempferol in 25 edible berries," Journal of Agricultural and Food Chemistry, vol. 47, no. 6, pp. 2274-2279, 1999. 
[45] G. Williamson and C. Manach, "Bioavailability and bioefficacy of polyphenols in humans. II. Review of 93 intervention studies," The American Journal of Clinical Nutrition, vol. 81, supplement 1, pp. 243S-255S, 2005.

[46] S. U. Lee, J. H. Lee, S. H. Choi et al., "Flavonoid content in fresh, home-processed, and light-exposed onions and in dehydrated commercial onion products," Journal of Agricultural and Food Chemistry, vol. 56, no. 18, pp. 8541-8548, 2008.

[47] G. S. Kelly, "Quercetin. Monograph," Alternative Medicine Review, vol. 16, no. 2, pp. 172-194, 2011.

[48] S. Egert, S. Wolffram, A. Bosy-Westphal et al., "Daily quercetin supplementation dose-dependently increases plasma quercetin concentrations in healthy humans," Journal of Nutrition, vol. 138, no. 9, pp. 1615-1621, 2008.

[49] I. Erlund, R. Freese, J. Marniemi, P. Hakala, and G. Alfthan, "Bioavailability of quercetin from berries and the diet," Nutrition and Cancer, vol. 54, no. 1, pp. 13-17, 2006.

[50] I. Erlund, J. Marniemi, P. Hakala, G. Alfthan, E. Meririnne, and A. Aro, "Consumption of black currants, lingonberries and bilberries increases serum quercetin concentrations," European Journal of Clinical Nutrition, vol. 57, no. 1, pp. 37-42, 2003.

[51] F. Jin, D. C. Nieman, R. A. Shanely, A. M. Knab, M. D. Austin, and W. Sha, "The variable plasma quercetin response to 12 week quercetin supplementation in humans," European Journal of Clinical Nutrition, vol. 64, no. 7, pp. 692-697, 2010.

[52] G. T. McAnlis, J. McEneny, J. Pearce, and I. S. Young, "Absorption and antioxidant effects of quercetin from onions, in man," European Journal of Clinical Nutrition, vol. 53, no. 2, pp. 92-96, 1999.

[53] T. Walle, A. M. Browning, L. L. Steed, S. G. Reed, and U. K. Walle, "Flavonoid glucosides are hydrolyzed and thus activated in the oral cavity in humans," Journal of Nutrition, vol. 135, no. 1, pp. 48-52, 2005.

[54] S. R. McAnulty, L. S. McAnulty, D. C. Nieman et al., "Chronic quercetin ingestion and exercise-induced oxidative damage and inflammation," Applied Physiology, Nutrition and Metabolism, vol. 33, no. 2, pp. 254-262, 2008.

[55] C. Angeloni, E. Leoncini, M. Malaguti, S. Angelini, P. Hrelia, and S. Hrelia, "Role of quercetin in modulating rat cardiomyocyte gene expression profile," American Journal of Physiology, vol. 294, no. 3, pp. H1233-H1243, 2008.

[56] C. Angeloni, J. P. E. Spencer, E. Leoncini, P. L. Biagi, and S. Hrelia, "Role of quercetin and its in vivo metabolites in protecting H9c2 cells against oxidative stress," Biochimie, vol. 89, no. 1, pp. 73-82, 2007.

[57] A. Annapurna, C. S. Reddy, R. B. Akondi, and S. R. C. Rao, "Cardioprotective actions of two bioflavonoids, quercetin and rutin, in experimental myocardial infarction in both normal and streptozotocin-induced type I diabetic rats," Journal of Pharmacy and Pharmacology, vol. 61, no. 10, pp. 1365-1374, 2009.

[58] K. J. Meyers, J. L. Rudolf, and A. E. Mitchell, "Influence of dietary quercetin on glutathione redox status in mice," Journal of Agricultural and Food Chemistry, vol. 56, no. 3, pp. 830-836, 2008.

[59] H. K. Park, S. J. Kim, D. Y. Kwon, J. H. Park, and Y. C. Kim, "Protective effect of quercetin against paraquat-induced lung injury in rats," Life Sciences, vol. 87, no. 5-6, pp. 181-186, 2010.

[60] M. Konrad, D. C. Nieman, D. A. Henson, K. M. Kennerly, F. Jin, and S. J. Wallner-Liebmann, "The acute effect of ingesting a quercetin-based supplement on exercise-induced inflammation and immune changes in runners," International Journal of Sport Nutrition and Exercise Metabolism, vol. 21, no. 4, pp. 338-346, 2011.

[61] D. C. Nieman, D. A. Henson, K. R. Maxwell et al., "Effects of quercetin and egcg on mitochondrial biogenesis and immunity," Medicine and Science in Sports and Exercise, vol. 41, no. 7, pp. 1467-1475, 2009.

[62] G. Askari, R. Ghiasvand, Z. Paknahad et al., "The effects of quercetin supplementation on body composition, exercise performance and muscle damage indices in athletes," International Journal of Preventive Medicine, vol. 4, no. 1, pp. 21-26, 2013.

[63] G. Askari, R. Ghiasvand, J. Karimian et al., "Does quercetin and vitamin $\mathrm{C}$ improve exercise performance, muscle damage, and body composition in male athletes?" Journal of Research in Medical Sciences, vol. 17, no. 4, pp. 328-331, 2012.

[64] Z. Lappalainen, "Sirtuins: a family of proteins with implications for human performance and exercise physiology," Research in Sports Medicine, vol. 19, no. 1, pp. 53-65, 2011.

[65] S. Chung, H. Yao, S. Caito, J. Hwang, G. Arunachalam, and I. Rahman, "Regulation of SIRT1 in cellular functions: role of polyphenols," Archives of Biochemistry and Biophysics, vol. 501, no. 1, pp. 79-90, 2010.

[66] J. M. Davis, E. A. Murphy, M. D. Carmichael, and B. Davis, "Quercetin increases brain and muscle mitochondrial biogenesis and exercise tolerance," American Journal of Physiology, vol. 296, no. 4, pp. R1071-R1077, 2009.

[67] J. M. Davis, C. J. Carlstedt, S. Chen, M. D. Carmichael, and E. A. Murphy, "The dietary flavonoid quercetin increases $\mathrm{VO}(2 \mathrm{max})$ and endurance capacity," International Journal of Sport Nutrition and Exercise Metabolism, vol. 20, no. 1, pp. 5662, 2010.

[68] D. C. Nieman, A. S. Williams, R. A. Shanely et al., "Quercetin's influence on exercise performance and muscle mitochondrial biogenesis," Medicine and Science in Sports and Exercise, vol. 42, no. 2, pp. 338-345, 2010.

[69] H. S.-H. MacRae and K. M. Mefferd, "Dietary antioxidant supplementation combined with quercetin improves cycling time trial performance," International Journal of Sport Nutrition and Exercise Metabolism, vol. 16, no. 4, pp. 405-419, 2006.

[70] K. A. Bigelman, E. H. Fan, D. P. Chapman, E. C. Freese, J. L. Trilk, and K. J. Cureton, "Effects of six weeks of quercetin supplementation on physical performance in ROTC cadets," Military Medicine, vol. 175, no. 10, pp. 791-798, 2010.

[71] K. J. Cureton, P. D. Tomporowski, A. Singhal et al., "Dietary quercetin supplementation is not ergogenic in untrained men," Journal of Applied Physiology, vol. 107, no. 4, pp. 1095-1104, 2009.

[72] M. S. Ganio, L. E. Armstrong, E. C. Johnson et al., "Effect of quercetin supplementation on maximal oxygen uptake in men and women," Journal of Sports Sciences, vol. 28, no. 2, pp. 201208, 2010.

[73] A. C. Utter, D. C. Nieman, J. Kang et al., "Quercetin does not affect rating of perceived exertion in athletes during the western states endurance run," Research in Sports Medicine, vol. 17, no. 2, pp. 71-83, 2009.

[74] J. Kressler, M. Millard-Stafford, and G. L. Warren, "Quercetin and endurance exercise capacity: a systematic review and metaanalysis," Medicine and Science in Sports and Exercise, vol. 43, no. 12, pp. 2396-2404, 2011.

[75] S. P. Alexander, "Flavonoids as antagonists at A1 adenosine receptors," Phytotherapy Research, vol. 20, no. 11, pp. 1009-1012, 2006. 
[76] M. S. Ganio, J. F. Klau, D. J. Casa, L. E. Armstrong, and C. M. Maresh, "Effect of caffeine on sport-specific endurance performance: a systematic review," Journal of Strength and Conditioning Research, vol. 23, no. 1, pp. 315-324, 2009.

[77] S. N. Cheuvront, B. R. Ely, R. W. Kenefick, B. B. MichniakKohn, J. C. Rood, and M. N. Sawka, "No effect of nutritional adenosine receptor antagonists on exercise performance in the heat," American Journal of Physiology, vol. 296, no. 2, pp. R394R401, 2009.

[78] A. Bordoni, S. Hrelia, C. Angeloni et al., "Green tea protection of hypoxia/reoxygenation injury in cultured cardiac cells," Journal of Nutritional Biochemistry, vol. 13, no. 2, pp. 103-111, 2002.

[79] Y. Naito and T. Yoshikawa, "Green tea and heart health," Journal of Cardiovascular Pharmacology, vol. 54, no. 5, pp. 385-390, 2009.

[80] K. Chyu, S. M. Babbidge, X. Zhao et al., "Differential effects of green tea-derived catechin on developing versus established atherosclerosis in apolipoprotein E-null mice," Circulation, vol. 109, no. 20, pp. 2448-2453, 2004.

[81] D. Chen, S. B. Wan, H. Yang, J. Yuan, T. H. Chan, and Q. P. Dou, "EGCG, green tea polyphenols and their synthetic analogs and prodrugs for human cancer prevention and treatment," Advances in Clinical Chemistry, vol. 53, pp. 155-177, 2011.

[82] B. N. Singh, S. Shankar, and R. K. Srivastava, "Green tea catechin, epigallocatechin-3-gallate (EGCG): mechanisms, perspectives and clinical applications," Biochemical Pharmacology, vol. 82, no. 12, pp. 1807-1821, 2011.

[83] S. Haramizu, N. Ota, T. Hase, and T. Murase, "Catechins attenuate eccentric exercise-induced inflammation and loss of force production in muscle in senescence-accelerated mice," Journal of Applied Physiology, vol. 111, no. 6, pp. 1654-1663, 2011.

[84] T. Murase, S. Haramizu, A. Shimotoyodome, A. Nagasawa, and I. Tokimitsu, "Green tea extract improves endurance capacity and increases muscle lipid oxidation in mice," American Journal of Physiology, vol. 288, no. 3, pp. R708-R715, 2005.

[85] S. Sae-Tan, K. A. Grove, M. J. Kennett, and J. D. Lambert, “(-)epigallocatechin-3-gallate increases the expression of genes related to fat oxidation in the skeletal muscle of high fat-fed mice," Food and Function, vol. 2, no. 2, pp. 111-116, 2011.

[86] A. G. Dulloo, C. Duret, D. Rohrer et al., "Efficacy of a green tea extract rich in catechin polyphenols and caffeine in increasing 24-h energy expenditure and fat oxidation in humans," American Journal of Clinical Nutrition, vol. 70, no. 6, pp. 1040-1045, 1999.

[87] M. C. Venables, C. J. Hulston, H. R. Cox, and A. E. Jeukendrup, "Green tea extract ingestion, fat oxidation, and glucose tolerance in healthy humans," American Journal of Clinical Nutrition, vol. 87, no. 3, pp. 778-784, 2008.

[88] J. C. Richards, M. C. Lonac, T. K. Johnson, M. M. Schweder, and C. Bell, "Epigallocatechin-3-gallate increases maximal oxygen uptake in adult humans," Medicine and Science in Sports and Exercise, vol. 42, no. 4, pp. 739-744, 2010.

[89] S. Dean, A. Braakhuis, and C. Paton, "The effects of EGCG on fat oxidation and endurance performance in male cyclists," International Journal of Sport Nutrition and Exercise Metabolism, vol. 19, no. 6, pp. 624-644, 2009.

[90] P. Eichenberger, P. C. Colombani, and S. Mettler, "Effects of 3-week consumption of green tea extracts on whole-body metabolism during cycling exercise in endurance-trained men," International Journal for Vitamin and Nutrition Research, vol. 79, no. 1, pp. 24-33, 2009.
[91] E. Jowko, J. Sacharuk, B. Balasinska et al., "Effect of a single dose of green tea polyphenols on the blood markers of exerciseinduced oxidative stress in soccer players," International Journal of Sport Nutrition and Exercise Metabolism, vol. 22, no. 6, pp. 486-496, 2012.

[92] G. Petrovski, N. Gurusamy, and D. K. Das, "Resveratrol in cardiovascular health and disease," Annals of the New York Academy of Sciences, vol. 1215, no. 1, pp. 22-33, 2011.

[93] T. Murase, S. Haramizu, N. Ota, and T. Hase, "Suppression of the aging-associated decline in physical performance by a combination of resveratrol intake and habitual exercise in senescence-accelerated mice," Biogerontology, vol. 10, no. 4, pp. 423-434, 2009.

[94] S. Dal-Ros, J. Zoll, A. Lang et al., "Chronic intake of red wine polyphenols by young rats prevents aging-induced endothelial dysfunction and decline in physical performance: role of NADPH oxidase," Biochemical and Biophysical Research Communications, vol. 404, no. 2, pp. 743-749, 2011.

[95] Y. C. Shen, J. C. Yen, and K. T. Liou, "Ameliorative effects of caffeic acid phenethyl ester on an eccentric exercise-induced skeletal muscle injury by down-regulating NF-kappaB mediated inflammation," Pharmacology, vol. 91, no. 3-4, pp. 219-228, 2013.

[96] Y. Chen, A. Huang, H. Chang et al., "Caffeic acid phenethyl ester, an antioxidant from propolis, protects peripheral blood mononuclear cells of competitive cyclists against hyperthermal stress," Journal of Food Science, vol. 74, no. 6, pp. H162-H167, 2009.

[97] R. D. Hurst, R. W. Wells, S. M. Hurst, T. K. McGhie, J. M. Cooney, and D. J. Jensen, "Blueberry fruit polyphenolics suppress oxidative stressinduced skeletal muscle cell damage in vitro," Molecular Nutrition and Food Research, vol. 54, no. 3, pp. 353-363, 2010.

[98] K. Nakazato, E. Ochi, and T. Waga, "Dietary apple polyphenols have preventive effects against lengthening contractioninduced muscle injuries," Molecular Nutrition and Food Research, vol. 54, no. 3, pp. 364-372, 2010.

[99] M. S. L. Swamy, S. Naveen, D. Singsit, M. Naika, and F. Khanum, "Anti-fatigue effects of polyphenols extracted from pomegranate peel," International Journal of Integrative Biology, vol. 11, no. 2, pp. 69-72, 2011.

[100] J. Allgrove, E. Farrell, M. Gleeson, G. Williamson, and K. Cooper, “Regular dark chocolate consumption's reduction of oxidative stress and increase of free-fatty-acid mobilization in response to prolonged cycling," International Journal of Sport Nutrition and Exercise Metabolism, vol. 21, no. 2, pp. 113-123, 2011.

[101] G. Davison, R. Callister, G. Williamson, K. A. Cooper, and M. Gleeson, "The effect of acute pre-exercise dark chocolate consumption on plasma antioxidant status, oxidative stress and immunoendocrine responses to prolonged exercise," European Journal of Nutrition, vol. 51, no. 1, pp. 69-79, 2011.

[102] J. K. Oh, Y. O. Shin, J. H. Yoon et al., "Effect of supplementation with Ecklonia cava polyphenol on endurance performance of college students," International Journal of Sport Nutrition and Exercise Metabolism, vol. 20, no. 1, pp. 72-79, 2010. 


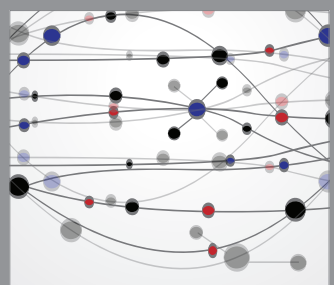

The Scientific World Journal
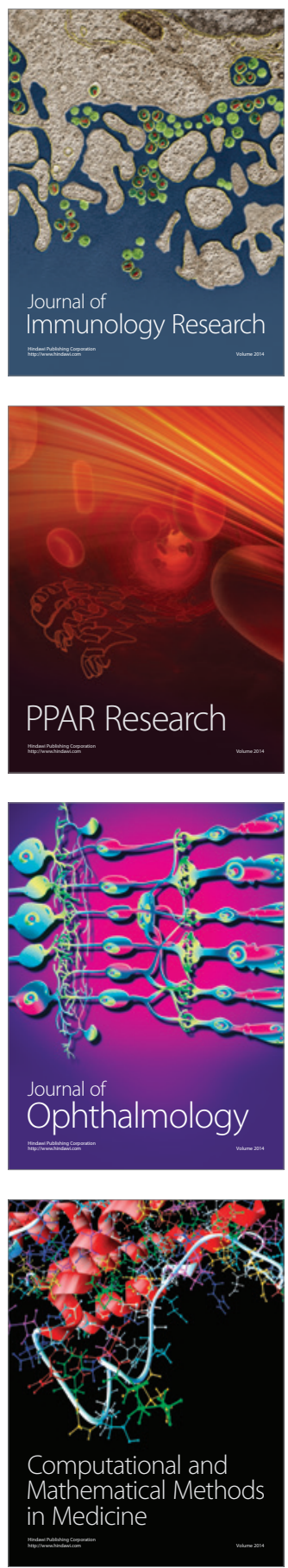

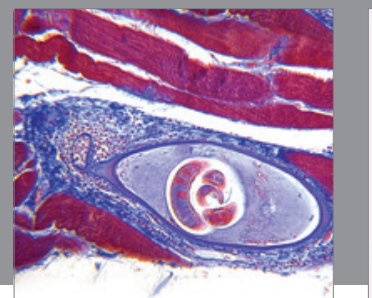

Gastroenterology

Research and Practice
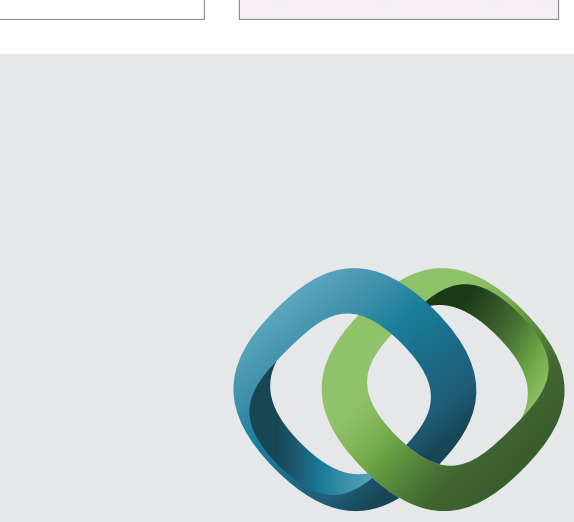

\section{Hindawi}

Submit your manuscripts at

http://www.hindawi.com
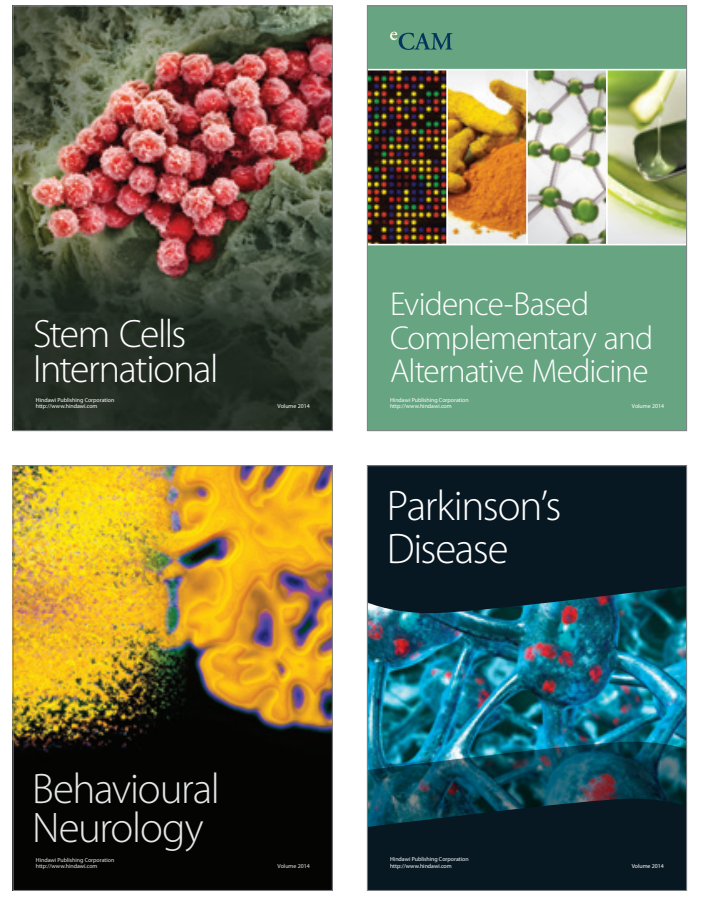
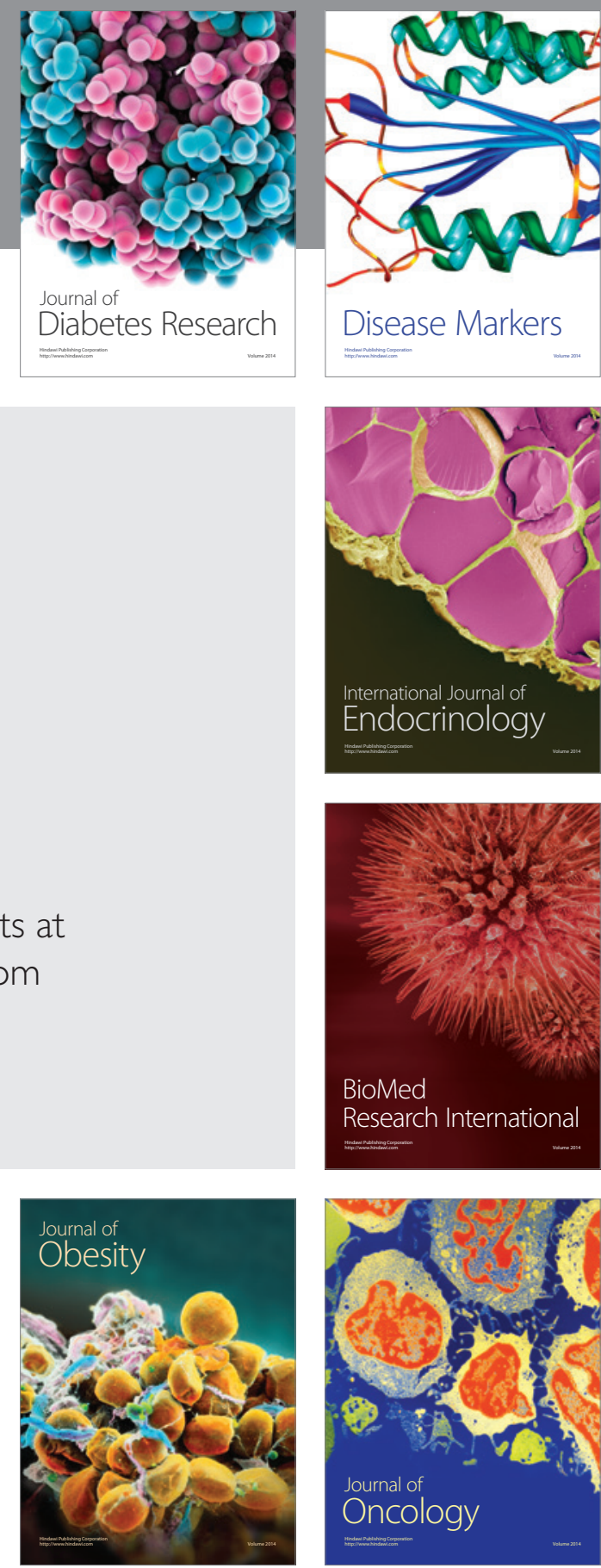

Disease Markers
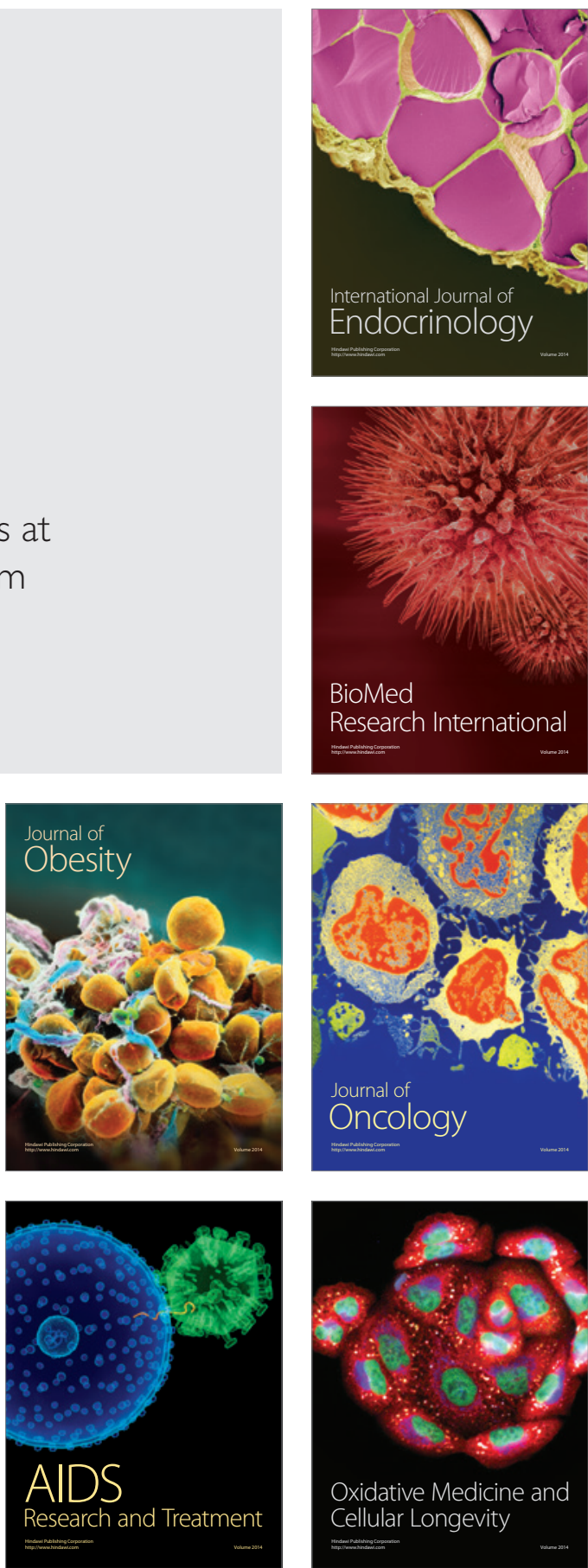